\title{
Erratum to: A Review on Mycosynthesis, Mechanism, and Characterization of Silver and Gold Nanoparticles
}

\author{
Kangkana Banerjee $^{1} \cdot$ V. Ravishankar Rai ${ }^{1}$
}

Published online: 11 September 2017

(C) Springer Science+Business Media, LLC 2017

Erratum to: BioNanoSci

https://doi.org/10.1007/s12668-017-0437-8

Unfortunately, there are errors in Figures 2, 3 and 4 in the original publication of the article. The 3 figures were interchanged. The correct versions are given below.

The original article was corrected.

The online version of the original article can be found at https://oi.org/ 10.1007/s12668-017-0437-8

\footnotetext{
V. Ravishankar Rai raivittal@gmail.com

1 Department of Studies in Microbiology, University of Mysore, Manasagangothri, Mysore, Karnataka 570006, India
} 


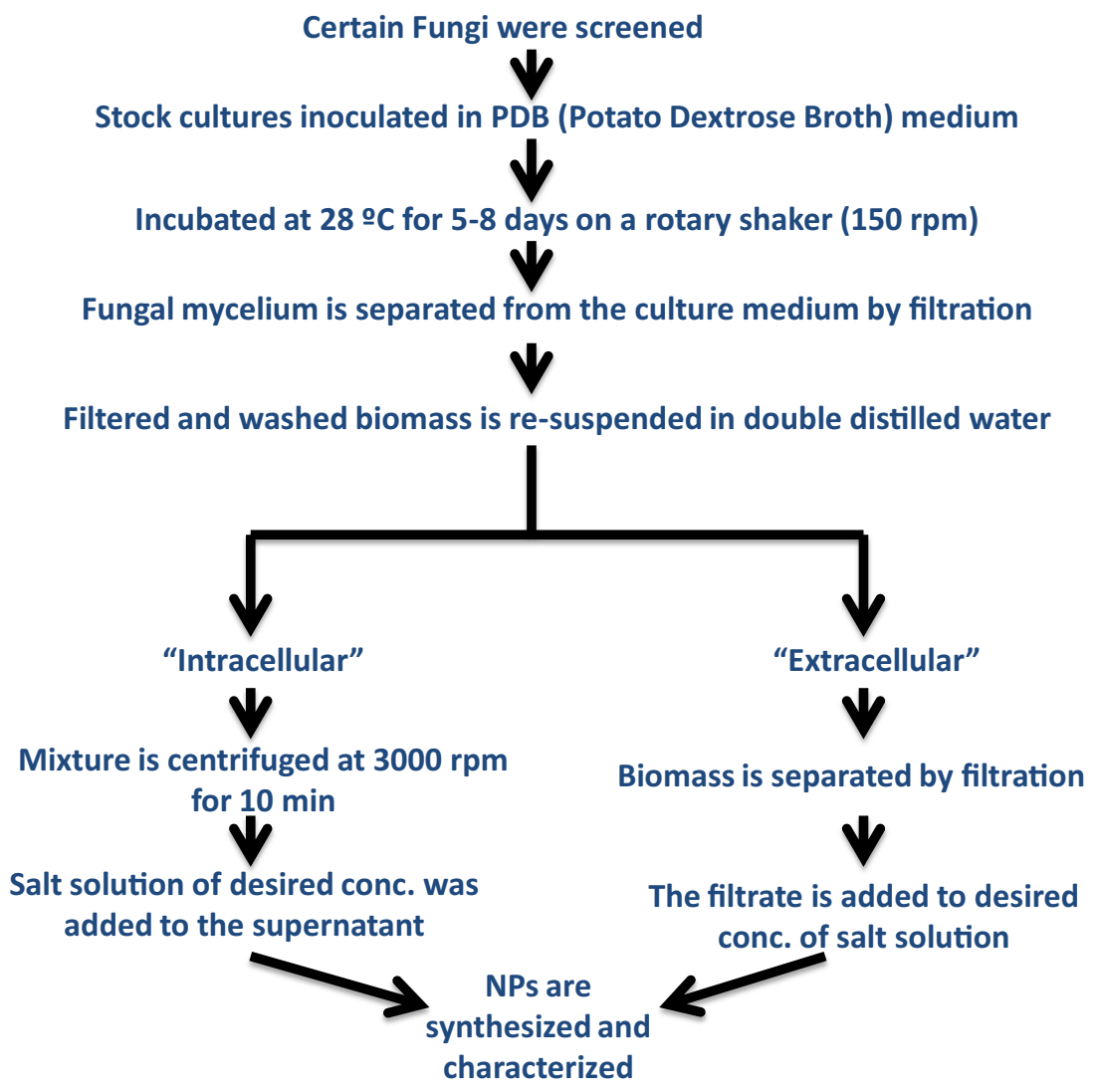

Fig. 2 Schematic representation of mycosynthesis of nanoparticles under extracellular and intracellular routes 

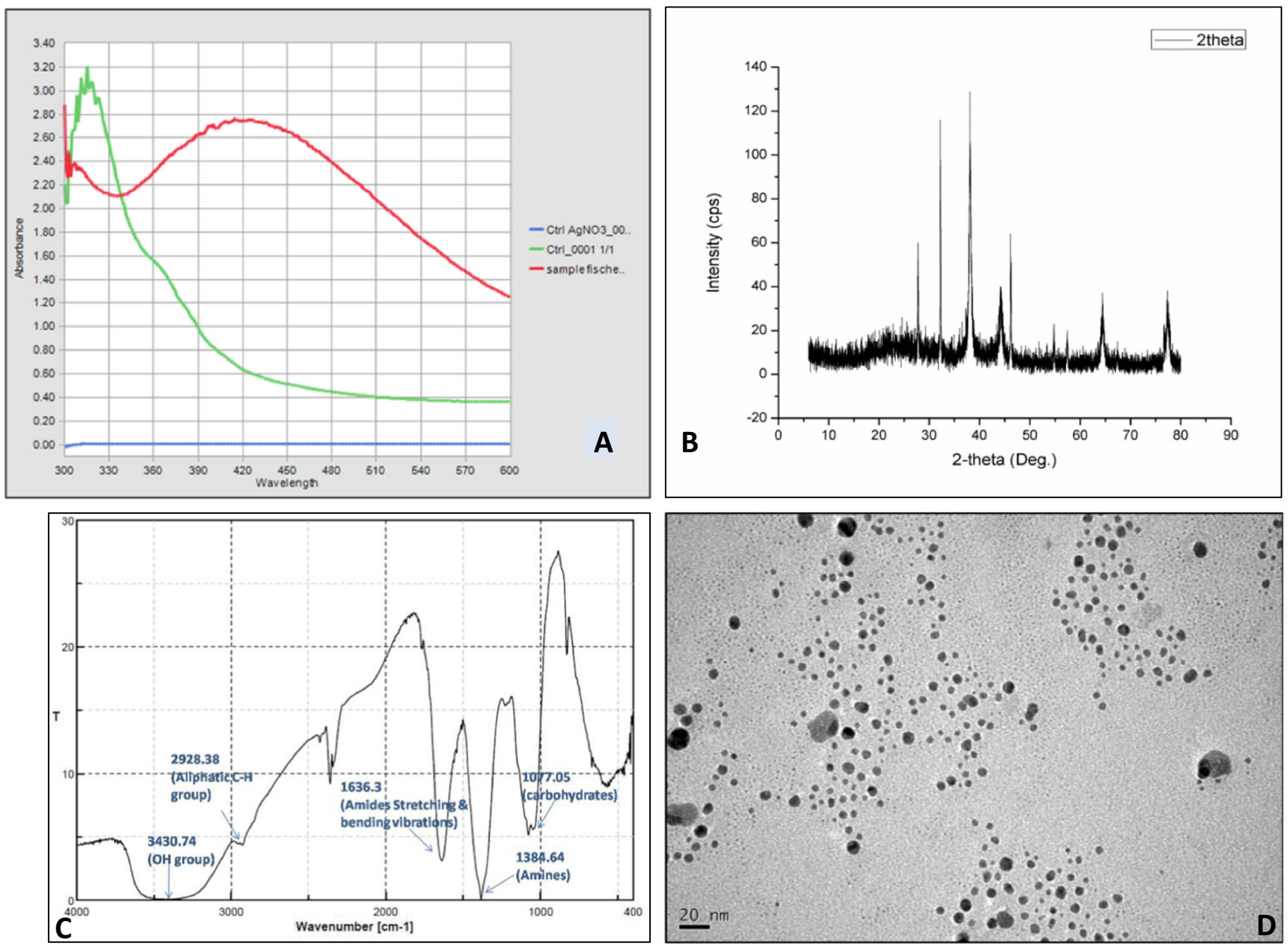

Fig. 3 Illustration of various characterization methods of silver nanoparticles (AgNPs) 

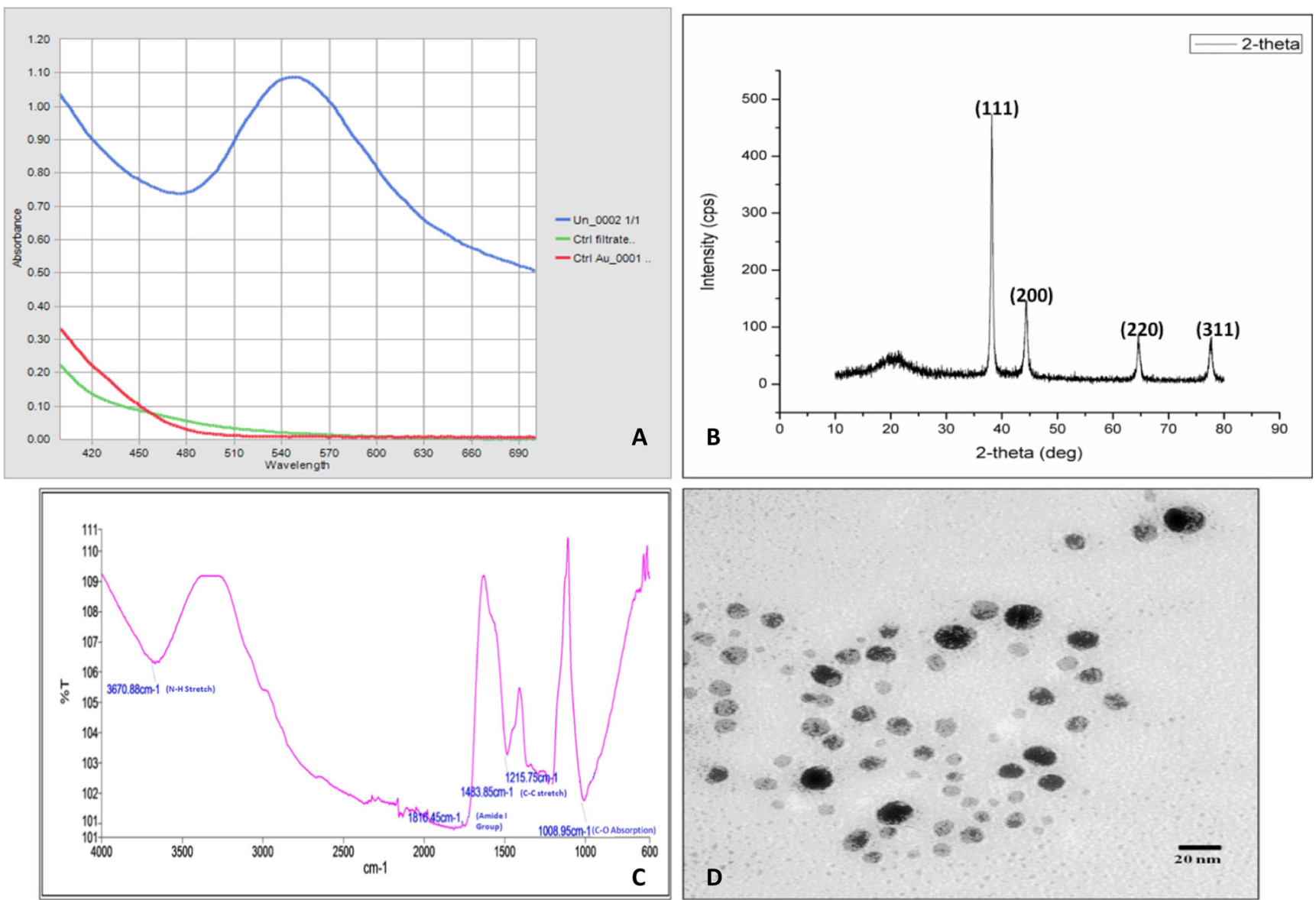

Fig. 4 Graphs depicting characterization methods of gold nanoparticles (AuNPs) 